\title{
PANORAMA DEMOGRÁFICO EN CHILE CONTEMPORÁNEO: DESAFÍOS PARA LA SOCIEDAD DEL SIGLO XXI
}

Gustavo Villalón Cárdenas y Sergio Vera Schneider 


\section{GUSTAVO VILLALÓN CÁRDENAS}

Profesor de Estado en Matemáticas, Universidad de Chile. Magíster en Demografía, CELADE/CEPAL. Es candidato a Doctor en Demografía de la Facultad de Ciencias Económicas de la Universidad Nacional de Córdoba, Argentina. Actualmente es jefe del Subdepartamento de Estadísticas Demográficas del Instituto Nacional de Estadísticas (INE) y profesor de la Universidad de Los Lagos.

\section{SERGIO VERA SCHNEIDER}

Estadístico, Universidad Austral de Chile. Magíster en Estadística Médica, London University, Inglaterra. Es candidato a Doctor en Demografía de la Facultad de Ciencias Económicas de la Universidad Nacional de Córdoba, Argentina. Actualmente se desempeña como analista demógrafo en el Subdepartamento de Estadísticas Demográficas del Instituto Nacional de Estadísticas (INE). 


\section{PANORAMA DEMOGRÁFICO EN CHILE CONTEMPORÁNEO: DESAFÍOS PARA LA SOCIEDAD DEL SIGLO XXI}

\section{INTRODUCCIÓN}

Este estudio trata sobre los cambios demográficos que ocurrieron en la población desde 1950 hasta el día de hoy, aunque algunos de los procesos que los desencadenaron, sin embargo, sucedieron con anterioridad, principalmente debido a la implementación de políticas públicas en Chile y su persistencia en el tiempo.

La información utilizada proviene principalmente de tres fuentes: los Censos de Población, las Estadísticas Vitales (nacimientos y defunciones) de las últimas seis décadas y las Proyecciones de Población del País 1950-2050.

El propósito del estudio es proporcionar a la sociedad chilena una visión de la evolución demográfica de nuestro país, enfocada principalmente en los cambios de la natalidad, la mortalidad y la migración, los tres componentes que determinan el crecimiento demográfico. Incluye un breve relato de las dos transiciones que influyeron en los cambios demográficos en Chile: la socioeconómica y la epidemiológica. Finalmente, reflexiona sobre un eventual escenario futuro de nuestra sociedad desde el punto de vista demográfico.

\section{¿CÓMO SE HAN MANIFESTADO LOS CAMBIOS DEL RITMO PROMEDIO DE CRECIMIENTO DE LA POBLACIÓN? ¿A QUÉ SE DEBIERON?}

En el escenario actual, la población de Chile crece a un ritmo promedio anual de 0,9 habitantes por cada cien ${ }^{1}$, en tanto que en la década de los años 50, esto es, entre 1952 y comienzos de los años 1960, la población del país crecía anualmente a un ritmo de 2,5 personas promedio por cada cien habitantes, el más intenso registrado en el perío-

1. Independiente de que esta cifra es muy inferior a la del pasado, y a modo de distinguir si este crecimiento es alto, mediano o bajo, se puede señalar que la disminución del crecimiento promedio de la población es una tendencia mundial actual. Por ejemplo, comparando con algunos países, el ritmo de crecimiento total promedio de la población sería negativo: Japón y Alemania, desde 2005; Italia y Cuba, desde 2010; China y Finlandia, desde 2030; España, desde 2040. Desde 2010, Japón sería el país con el más intenso descenso de su población en el mundo, de 0,2 promedio anual por cada cien habitantes. También Japón es el país más envejecido del mundo. En Latinoamérica, Costa Rica, Brasil y Argentina tienen un crecimiento promedio algo mayor que Chile $(1,3 ; 1,1 ;$ y 0,93 por cien habitantes, respectivamente). En tanto, Uruguay crece a un ritmo que es solo un tercio del chileno (0,3 habitantes promedio por cada cien). El ritmo de crecimiento promedio de Chile es similar al de Estados Unidos, algo superior al de Nueva Zelanda (0,8 por cien personas promedio anual) y algo menor que el de Australia $(0,95$ habitantes promedio por cada cien). (Fuente: Naciones Unidas, World Population Prospects: The 2006 Revision). 
do. Este crecimiento se debió, principalmente, a la ostensible baja de la mortalidad, especialmente la infantil, y a la mantención de la natalidad en niveles moderadamente altos $^{2}$. Así, el crecimiento de la población de Chile se asocia a un largo y sostenido proceso de expansión demográfica (Cuadro 1).

\section{Cuadro 1}

POBLACIÓN TOTAL Y TASA DE CRECIMIENTO MEDIO ANUAL (TCMA) DE LA POBLACIÓN. CENSOS 1813-2002

\begin{tabular}{|c|c|c|}
\hline Censo & Población & $\begin{array}{c}\text { TCMA } \\
\text { (por cien habs.) }\end{array}$ \\
\hline 1813 & 823.685 & - \\
\hline 1835 & 1.010 .336 & - \\
\hline 1843 & 1.083 .801 & 0,88 \\
\hline 1854 & 1.439 .120 & 2,69 \\
\hline 1865 & 1.819 .223 & 2,13 \\
\hline 1875 & 2.075 .971 & 1,32 \\
\hline 1885 & 2.527 .320 & 1,86 \\
\hline 1895 & 2.687 .985 & 0,62 \\
\hline 1907 & 3.249 .279 & 1,58 \\
\hline 1920 & 3.753 .799 & 1,11 \\
\hline 1930 & 4.287 .445 & 1,34 \\
\hline 1940 & 5.023 .539 & 1,58 \\
\hline 1952 & 5.932 .995 & 1,46 \\
\hline 1960 & 7.374 .115 & 2,53 \\
\hline 1970 & 8.884 .768 & 1,98 \\
\hline 1982 & 11.329 .736 & 2,03 \\
\hline 1992 & 13.348 .401 & 1,64 \\
\hline 2002 & 15.116 .435 & 1,24 \\
\hline
\end{tabular}

Nota: El Censo de 1813 es un recuento. Incluye desde la provincia de Copiapó a Concepción, excluyendo Santiago.

Fuente: INE, Los Censos de Población en Chile y su evolución histórica hacia el bicentenario; Censos Nacionales de Población, 1835-2002.

\section{CAMBIOS DEMOGRÁFICOS DESDE MEDIADOS DEL SIGLO XX}

A mediados del siglo XX, Chile tenía alrededor de seis millones de habitantes: las mujeres que concluían su período fértil (15-49 años) tenían, en promedio, cinco hijas e hijos

2. Entre 1940 y 1960 , en Chile la tasa bruta de mortalidad bajó de 21 a 13 defunciones promedio por mil habitantes. Por su parte, la tasa bruta de natalidad aumentó de 36 a 38 nacimientos promedio por mil habitantes. En consecuencia el crecimiento natural, esto es, la diferencia entre la natalidad y la mortalidad, aumentó de 15 a 25 personas promedio por cada mil habitantes en el período. 
por mujer³; la esperanza de vida al nacer era de 55 años (53 el hombre y 57 la mujer) ${ }^{4}$; de cada mil niños que nacían, 120 morían antes del primer año de vida; por cada mil habitantes, anualmente emigraban del país 1,3 personas en promedio ${ }^{5}$; la edad promedio de la población era de 26 años, en tanto que había solamente 19 adultos mayores por cada cien menores de 15 años ${ }^{6}$.

Hoy, el país tiene 17,4 millones de habitantes, las mujeres aportan, en promedio, 1,9 hijas e hijos por mujer (INE, 2011), un recién nacido tiene una esperanza de vida de 79 años (76 el hombre y 82 la mujer). Por cada mil niños nacidos vivos, aproximadamente 8 , en promedio, mueren antes del primer cumpleaños (INE, 2011). Por cada mil habitantes, 0,2 son inmigrantes al país, promedio anual ${ }^{7}$. La edad promedio de la población es de 35 años, en tanto que hay 63 adultos mayores por cada cien menores de 15 años.

Expresando comparativamente la situación demográfica del país en la actualidad respecto de 1950, en términos absolutos y relativos:

El ritmo de crecimiento promedio anual de nuestra población es hoy algo menos de la tercera parte, esto es, disminuyó un $64 \%{ }^{8}$.

La población total del país aumentó en 11,3 millones de habitantes, vale decir, casi se triplicó.

El nivel de fecundidad promedio disminuyó en 3,1 hijas e hijos por cada mujer, esto es, bajó un 62\% en aproximadamente 60 años.

La esperanza de vida al nacer aumentó 24,3 años, o sea, un 31\%.

3. Se refiere a la tasa global de fecundidad, que expresa el número promedio de hijas e hijas que ha tenido cada mujer que ha sobrevivido hasta el término de su período fértil (15-49 años).

4. La esperanza de vida al nacer expresa el número promedio de años que se espera pueda vivir un(a) recién nacido(a) en un año y territorio dados.

5. Se refiere a la tasa de migración neta internacional, que expresa el número medio anual de personas migrantes internacionales del país por cada mil habitantes. Si la tasa es positiva, la inmigración es superior a la emigración; si es negativa, la inmigración es inferior a la emigración; si es nula, la inmigración es igual a la emigración.

6. Se refiere al Índice de Adultos Mayores (IAM), que expresa el número de personas de 60 años o más de edad por cada cien menores de 15 años. El IAM es una medida del envejecimiento demográfico de una población.

7. La migración internacional, junto a la mortalidad y la fecundidad, constituyen los denominados componentes del crecimiento demográfico de la población.

8. Téngae en cuenta que el descenso del ritmo de crecimiento promedio de una población no implica que la población disminuya sino que, por el contrario, sigue creciendo, aunque a una menor velocidad que antes. 
La mortalidad infantil descendió en 112 niños por cada mil nacidos vivos, esto es, un $93 \%$.

Hoy Chile es un país que recibe inmigrantes, antes era de emigración.

La edad promedio aumentó en 8,3 años, vale decir, un 32\%.

Hoy día hay 44 adultos mayores más por cada cien menores de 15 años, lo que significa que el envejecimiento demográfico actual es algo superior al triple de aquel de mediados del siglo XX.

\section{¿CÓMO PUEDEN EXPLICARSE LOS CAMBIOS DEMOGRÁFICOS A TRAVÉS DEL TIEMPO?}

Esta síntesis descriptiva de los cambios demográficos experimentados por la población del país a través del tiempo, asociados a una evolución de larga duración, se pueden explicar a consecuencia de la incidencia de dos procesos, la transición socioeconómica y la transición epidemiológica, derivando en un efecto conjunto, en el proceso denominado de transición demográfica, caracterizada por la tendencia hacia el envejecimiento demográfico de la población.

\section{¿CUÁLES SON ESOS PROCESOS DE EVOLUCIÓN SOCIAL, ECONÓMICA Y DEMOGRÁFICA, Y EN QUÉ MOMENTO Y CIRCUNSTANCIAS SE INICIARON? ¿CÓMO SE VINCULAN ENTRE SÍ? ¿CONCLUYERON O ESTÁN AÚN VIGENTES?}

Son tres procesos de larga duración que se han dado en forma paralela, con sus propios momentos históricos de ocurrencia, con sus respectivos ritmos de evolución, con diferentes patrones de cambio y especificidades, heterogéneos pero complementarios en tanto aportan a la comprensión de la dinámica del cambio social, económico, cultural y demográfico de la sociedad chilena.

El primero de ellos se refiere a los cambios socioeconómicos relativos a las transformaciones sociales y económicas ocurridas en el país desde los años 30 y principalmente a partir de los años 60 del siglo XX, esto es, la llamada transición socioeconómica. El segundo es la transición epidemiológica y se refiere a los cambios en el tiempo de la composición de la mortalidad por sexo y edades y a las modificaciones en las causas de muerte. Este proceso da cuenta tanto del descenso como de cambios en la estructura de la mortalidad, ocurridos en el país desde los años 50 y con marcada intensidad en los últimos cuarenta años.

Estos dos procesos de cambios a través del tiempo, la transición socioeconómica y la transición epidemiológica inciden directamente en el tercer proceso de larga duración, la denominada transición demográfica. Esta se refiere a los cambios a través del tiempo 
desde niveles altos a bajos de la mortalidad y de la fecundidad. Este proceso da cuenta de los cambios demográficos ocurridos en el país durante el siglo XX y, en particular, con mayor intensidad a partir de la década de los años 60.

Estos distintos procesos se han dado en Chile durante el siglo XX y están aún en curso. En especial, a través de los últimos treinta años se han producido intensas modificaciones en los patrones de la evolución social, económica, epidemiológica y demográfica de la población.

A través de este estudio analizaremos algunas variables insertas tanto en la transición socioeconómica como en la epidemiológica, dimensiones ambas que afectan e influyen en las modificaciones en el tiempo de los componentes demográficos (la fecundidad, la mortalidad y la migración internacional).

\section{TRANSICIÓN SOCIOECONÓMICA}

Se llamará "transición socioeconómica", en este estudio, a los cambios sociales y económicos que ocurrieron en la segunda mitad del siglo XX y primera década del siglo XXI, observados a través de los censos de población. Estos, de una forma u otra, produjeron cambios en la población, provocando a su vez la denominada "transición demográfica". Los datos que serán utilizados en esta sección corresponden a la información derivada de los últimos seis censos de población (1952-2002).

Para referirse a los cambios sociales y económicos se mencionarán algunos hitos que marcaron la historia de nuestro país. Entre los más importantes destacamos la urbanización de nuestra sociedad ${ }^{9}$, esto es, el aumento vertiginoso de la población urbana concentrada en ciudades y pueblos. Este es un proceso que se inicia después de los años 50, como se puede observar en el Gráfico 1. A inicios del siglo XX en Chile, la población, tanto urbana como rural, crecía a un ritmo promedio parejo y muy lentamente. Por ejemplo, en 1940, 2,6 millones de habitantes vivían en el área urbana versus 2,4 millones en la rural (INE, 1941). Después de los años 50 comienzan a surgir las diferencias entre estas dos poblaciones: se acelera considerablemente el ritmo de crecimiento de la población urbana mientras que la población rural, en términos porcentuales, disminuyó su contribución al total, cada vez más.

9. El concepto urbano-rural ha cambiado a través de los censos, siendo que en rigor son comparables solo los censos de población de 1982, 1992 y 2002. Sin embargo, el cambio de concepto no invalida el análisis aquí presentado, ya que entenderemos por urbanización el porcentaje de población urbana. 


\section{Gráfico 1}

PORCENTAJE DE POBLACIÓN URBANA-RURAL, SEGÚN CENSOS DE POBLACIÓN 1952-2002

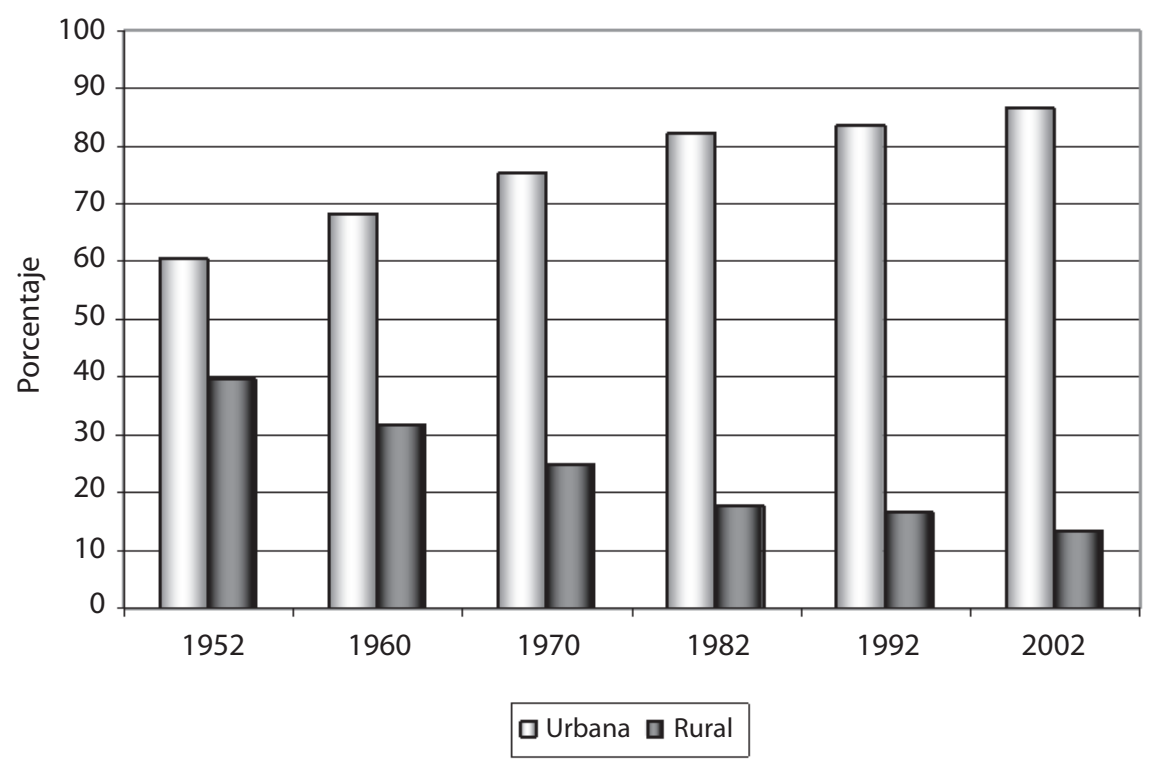

Fuente: INE, Censos de Población 1952-2002.

En términos del ritmo de crecimiento promedio anual, el área urbana llegó a crecer hasta 43 personas por mil habitantes en la década de los 50, para después disminuir su ritmo, llegando a fines del siglo XX e inicios del siglo XXI a 16 por mil.

Un segundo factor, atribuido al cambio socioeconómico de nuestro país, es el aumento de la población alfabetizada y del nivel educacional, siendo factores de relevancia para el desarrollo sociocultural de cualquier sociedad. Con el aumento de la educación y su universalización, tienden a disminuir las brechas dentro de una sociedad, lo cual permite acelerar el desarrollo de la misma.

A inicios del siglo XX, aproximadamente la mitad de la población de 15 años o más se consideraba alfabeta (INE, 1908). En los años 50 el porcentaje de analfabetos había disminuido a menos de la mitad, siendo de aproximadamente 20\% (INE, 1956), y continuó bajando, hasta que en el primer censo del siglo XXI se declararon alfabetos un 96\% de la población de 15 años o más, sin diferencias relevantes por sexo (Gráfico 2).

Por otro lado, se tiene el nivel de escolaridad, representado a través del número medio de años de estudio aprobados. De acuerdo con el censo de 1960, la población en Chile tenía una escolaridad promedio de 5,4 años, aumentando a 6,4 en el censo de 1970, incrementándose en 1,4 años en el censo de 1982 respecto de 1970, y alcanzando a 9,2 años de estudio aprobados en el censo de 1992. Según el censo de 2002, la media de años de estudio en Chile fue de 10,1 para la población de 15 años o más. 


\section{Gráfico 2}

PORCENTAJE DE POBLACIÓN ALFABETIZADA (15 AÑOS O MÁS), SEGÚN CENSOS DE POBLACIÓN 1952-2002

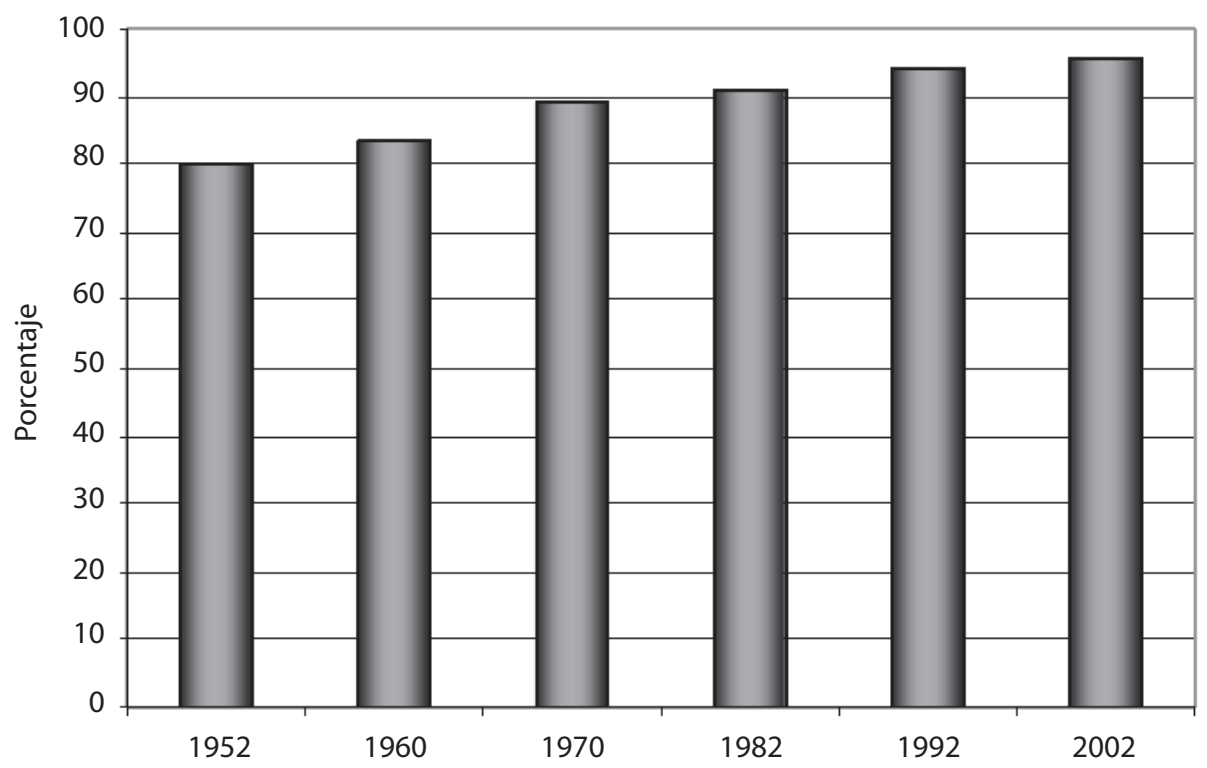

Fuente: INE, Censos de Población 1952-2002.

Aquí cabe resaltar algunos hitos en la educación chilena que han contribuido al aumento considerable del nivel educacional: en 1920 se dictó la Ley de Instrucción Primaria Obligatoria (Ley No 3654 del 20 de agosto de 1920); en 1928 se crearon las "Juntas Comunales de Auxilio Escolar" con el propósito de dar alimentación a todos los estudiantes de bajos recursos en escuelas públicas, de donde surgirían la "Junta Nacional de Auxilio Escolar" y la "Junta Nacional de Auxilio Escolar y Becas", en 1964 (Olavarría, 2005). En 1965 la Reforma Educacional extiende a ocho años la escolaridad obligatoria y el 7 de mayo de 2003 se promulga la Reforma Constitucional que establece la enseñanza media obligatoria y gratuita.

Otro de los cambios importantes por los cuales ha atravesado la población de nuestro país, en el contexto social, dice relación con el Estado Civil o Conyugal. Los censos de 1952 a 2002 dan cuenta de una transformación considerable en la distribución de esta variable. De acuerdo con el censo de la mitad del siglo XX, el porcentaje de población casada ha permanecido casi sin alteraciones, pasando de 48\% en los años 50 a 46\% en el censo de 2002. Pero lo más relevante de la distribución porcentual de esta variable, es el aumento entre los censos de 1952 y 2002 de la categoría conviviente/pareja, la cual triplicó su importancia relativa. Si bien es cierto que las uniones de hecho no son el grupo mayoritario, es la categoría que más aumento ha tenido a través de los últimos seis censos (Gráfico 3). 


\section{Gráfico 3}

DISTRIBUCIÓN PORCENTUAL DE LA POBLACIÓN POR ESTADO CIVIL O MARITAL, SEGÚN CENSOS DE POBLACIÓN 1952-2002

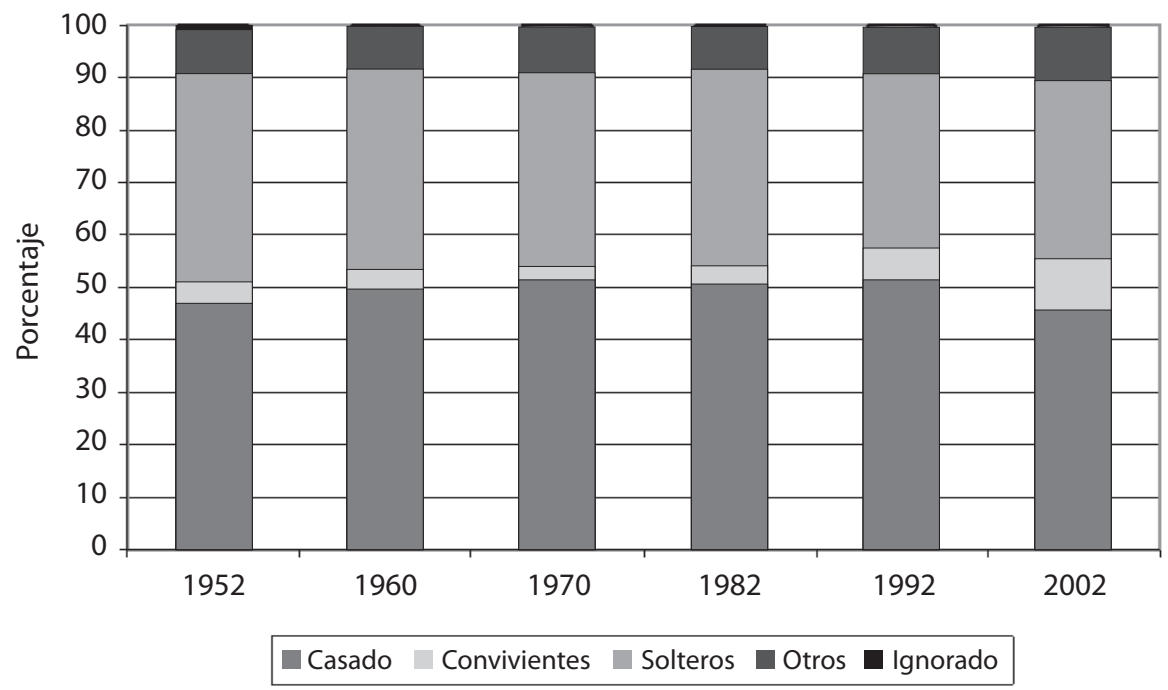

Fuente: INE, Censos de Población 1952-2002.

Finalmente, para cerrar esta visión de transición de la población, desde el punto de vista socioeconómico, y a partir de los censos de población, se observa otro cambio no menor en la evolución de la población ocupada, referente a los sectores económicos donde actúan. Así, el sector terciario ${ }^{10}$ de la producción ha aumentado considerablemente.

Analizando la concentración de la población de 15 años o más ocupada, según sectores económicos, desde los inicios del país y hasta alrededor de los años 60 predominaba el sector primario por sobre el secundario ${ }^{11}$ y el terciario.

De acuerdo con el censo de 1970, la población ocupada en el sector terciario constituía un 43\%, aumentando a 50\% en 1982 y a 56\% en 1992. Según el censo de 2002, este sector estaría constituido por un $67 \%$ de la población ocupada. De este modo, más de dos tercios de la población ocupada en Chile se desempeña en servicios, bancos, restaurantes, comunicaciones, comercio y afines, actividades localizadas principalmente en el área urbana (ciudades y pueblos), hecho que ha crecido relativamente rápido en los últimos treinta años, constituyendo una muestra de la expansión de la globalización.

Todos estos cambios son coherentes con el crecimiento económico del país. Chile creció a un ritmo de 3,86\% entre 1940 y 1973, y de 3,70\% en el período 1973-1990

10. El sector económico terciario está compuesto por las siguientes ramas de actividad económica de desempeño de la población de 15 años o más: comercio, restaurantes, hoteles, transporte, almacenamiento, comunicaciones, establecimientos financieros, seguros, bienes inmuebles y servicios prestados a las empresas, servicios comunales, sociales y personales.

11. El sector primario se caracteriza por actividades económicas del campo: minas y canteras, agricultura, forestal. El secundario se vincula con actividades manufactureras, industriales, etc. 
(Olavarría, 2005), exhibiendo su más alto crecimiento del ingreso per cápita promedio, de aproximadamente 5,4\%, entre 1984 y 1997.

Aunque con posterioridad a 1997 la velocidad de crecimiento económico del país se moderó notoriamente, ha mejorado su posición relativa respecto del crecimiento de otros países. Así, en 2009 el producto bruto interno per cápita de Chile representaba el 31\% del nivel de los Estados Unidos, el 37\% del G- $7^{12}$ y el 134\% de América Latina (Ffrench-Davis, 2011).

\section{TRANSICIÓN EPIDEMIOLÓGICA}

Se llamará "transición epidemiológica" a los cambios ocurridos en la composición de la morbi-mortalidad por sexo y edad en nuestro país. Sin embargo, en esta publicación nos referiremos exclusivamente a los cambios en la composición de la mortalidad entre 1960 y 2009.

La distribución porcentual de las defunciones, según los principales grupos de causas de muerte, ha variado en el tiempo. En los años 60, la mayoría de las defunciones se debían a enfermedades del sistema circulatorio (21\%), afecciones perinatales (14\%) y enfermedades del sistema digestivo (12\%). Luego, en los años 70 surge como el principal grupo de causas de muerte las defunciones por enfermedades del sistema circulatorio (22\%), que desde entonces permanece hasta hoy en primer lugar. El segundo grupo de causas de muerte, que surge en forma paulatina, y a diferencia de las enfermedades del sistema circulatorio, es el cáncer. Entre 1960 y 2009, su representatividad, en términos relativos, se triplicó, pasando de $8 \%$ a 26\%, respectivamente (Cuadro 2).

\section{Cuadro 2}

DISTRIBUCIÓN PORCENTUAL DE LAS DEFUNCIONES POR GRANDES GRUPOS DE CAUSAS DE MUERTE. 1960-2009

\begin{tabular}{|l|c|c|c|c|c|c|}
\hline Gran grupo de causas de muerte & 1960 & 1970 & 1980 & 1990 & 2000 & 2009 \\
\hline Sistema circulatorio & 8,7 & 21,9 & 26,6 & 26,4 & 27,9 & 27,0 \\
\hline Tumores & 8,4 & 12,1 & 15,8 & 18,1 & 24,2 & 25,6 \\
\hline Sistema respiratorio & 20,6 & 18,3 & 9,5 & 12,3 & 10,5 & 9,7 \\
\hline Causas externas de mortalidad & 7,2 & 9,7 & 11,9 & 12,2 & 9,8 & 8,9 \\
\hline Sistema digestivo & 11,9 & 6,5 & 8,1 & 7,8 & 7,2 & 7,3 \\
\hline Endocrinas, nutricionales y metabólicas & 0,7 & 2,6 & 2,5 & 2,3 & 4,2 & 4,7 \\
\hline Mal definidas & 8,7 & 5,5 & 9,6 & 7,3 & 3,9 & 2,6 \\
\hline Afecciones perinatales & 14,4 & 5,3 & 4,3 & 2,2 & 1,2 & 0,9 \\
\hline Infecciones y parasitarias & 8,7 & 11,6 & 3,0 & 3,2 & 2,6 & 2,0 \\
\hline Las demás causas & 10,6 & 6,4 & 8,6 & 8,2 & 8,5 & 11,4 \\
\hline
\end{tabular}

Fuente: DEIS-MINSAL.

12. El G-7 es el grupo de países de economías avanzadas: Estados Unidos, Alemania, Canadá, Francia, Japón, Reino Unido e Italia. 
En cuanto a la reducción de grupos de causas de muerte, cabe resaltar las del sistema respiratorio, las afecciones perinatales y las infecciosas y parasitarias, que en los casi 50 años de estudio disminuyeron su representatividad relativa en 53\%, 94\% y 77\%, respectivamente, del total de muertes.

Así, de forma general, hubo un cambio en el perfil de la mortalidad en los últimos 50 años que también trajo un cambio en el perfil de los grupos de edades de las defunciones. En los años 60, de las 95.486 muertes registradas, 34.314 (36\%) correspondían a menores de un año de edad y 21.480 (22\%) a personas de 65 años o más (INE, 1960). En cambio, en 2009, 2\% del total de muertes corresponden a menores de un año y $68 \%$ a personas de 65 años o más (INE, 2011). Esta información demuestra la importancia de la disminución de la mortalidad infantil, que bajó de aproximadamente 120 defunciones por cada mil nacidos vivos, en 1960, a aproximadamente 8 en 2009, esto es, una reducción del 93\% en medio siglo.

En este período, uno de los hitos más relevantes que contribuyeron en parte a los cambios anteriormente mencionados fue la creación del Servicio Nacional de Salud, en 1952. En la medida de su instalación, progresivamente se fueron desarrollando programas de relevancia para la sociedad como: control de desnutrición, diarrea infantil, vacunaciones ampliadas, control y atención profesional del embarazo y parto, fertilidad, entre otros (ARS MEDICA, 2001). La mantención sostenida de estos programas trajo cambios que fueron percibidos ya en el perfil epidemiológico de los años 70 .

\section{Gráfico 4}

TASA DE MORTALIDAD INFANTIL. 1960-2009

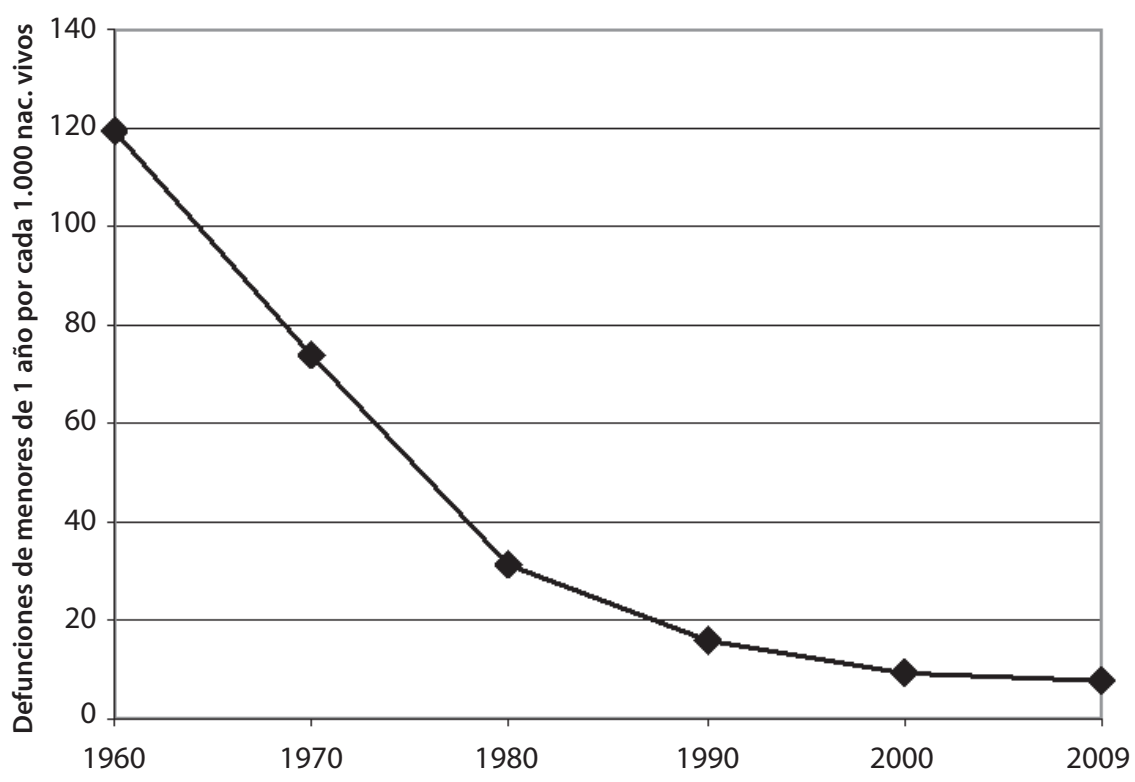

Fuente: INE, Estadísticas Vitales 1960-2009. 


\section{TRANSICIÓN DEMOGRÁFICA}

La transición demográfica se refiere a los cambios desde niveles altos a bajos de la mortalidad y de la fecundidad, en este caso experimentados en Chile y cuya consecuencia más inmediata es el cambio en la estructura por edad de la población, que influye en la disminución del porcentaje de población joven y el aumento de la concentración porcentual en las edades más avanzadas, que ocurre más tardíamente.

Los resultados de los censos de población entregan los datos y las herramientas para comprender mejor la realidad de la población en general y, en especial, de los adultos mayores (población de 60 años o más de edad o "minoría creciente"), a fin de que el país tienda a asumir la realidad del envejecimiento demográfico de la población y adecuar los nuevos enfoques de políticas sociales, en el ámbito económico y social, para encarar los desafíos inherentes.

Aunque este proceso de transición demográfica lleva prácticamente en Chile 80 años (la primera fase se inició en 1933 y la actual en 1961), aún no es asumido plenamente por la sociedad, si bien se reconocen algunas acciones desarrolladas a favor de la "minoría creciente" (por ejemplo, la atención gratuita de los adultos mayores en el sistema público de salud y la creación del SENAMA ${ }^{13}$ ).

El explosivo incremento de los adultos mayores está ligado a la baja sostenida de la mortalidad y al aumento de la longevidad, entendida como capacidad de sobrevivir de un año a otro gracias a los progresos en medicina preventiva y curativa, al descubrimiento y mejora de los medicamentos y vacunas, a la adopción de medidas sanitarias, entre otras.

Esta tendencia al envejecimiento afecta la demanda de bienes y servicios que requerirá la población en los próximos años, de modo que las políticas públicas tendrán que considerar las necesidades adicionales que surjan de las distintas etapas del ciclo de vida de las personas.

El envejecimiento demográfico de la población nos enfrenta, como país, al desafío de trabajar creativamente en la búsqueda de soluciones que se hagan cargo de esta realidad, abordando, en forma sistémica, las dimensiones demográfica, económica y social que provoca este fenómeno.

\section{¿CUÁL HA SIDO EL CRECIMIENTO NATURAL O VEGETATIVO EN CHILE?}

A continuación se presenta la evolución histórica del crecimiento natural o vegetativo de la población, componente central del cambio demográfico en Chile dada la relevancia

13. Servicio Nacional del Adulto Mayor, creado por la Ley 19.828, del 17 de septiembre de 2002. Esta ley define como adulto mayor a toda persona que ha cumplido 60 años, sin diferencia entre mujeres y hombres. 
menor que ha tenido el componente migratorio ${ }^{14}$. El Gráfico 5 da cuenta, a través del tiempo, del saldo de población resultante de la diferencia entre la tasa de nacimientos vivos (Tasa Bruta de Natalidad) y la tasa de defunciones generales (Tasa Bruta de Mortalidad).

Es importante destacar la contribución del crecimiento natural en términos cuantitativos a través del período en estudio, ya que su aporte ha sido predominante en el crecimiento total de la población de Chile, en tanto que el aporte de la migración neta internacional ha sido de menor cuantía.

\section{Gráfico 5}

TASA BRUTA DE NATALIDAD (TBN) Y DE MORTALIDAD (TBM). 1848-2009

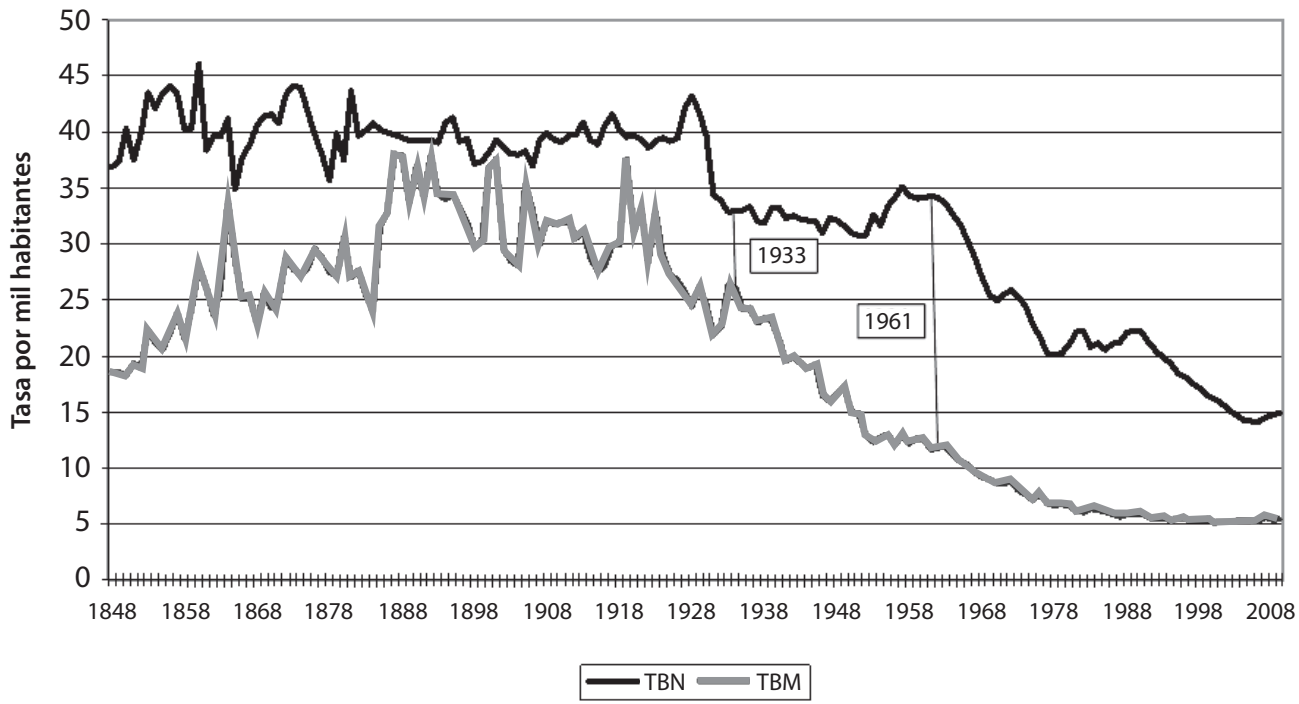

Fuentes: Para el cálculo de las tasas se utilizaron las Proyecciones de Población y las siguientes fuentes:

1. 1848-1849, INE, Anuario Estadístico 1912. Estadística retrospectiva del movimiento del estado civil, Cuadro II, pág. 173; 1850-1883, INE, Anuario Estadístico de la República de Chile, Volumen I. Demografía, Año 1923, Estadística retrospectiva, Cuadro 1, pág. 80.

2. 1884-1903, INE, Movimiento de población, en Población de Chile, año de 1903.

3. 1904-1930, INE, Anuario Estadístico de Chile, Volumen I. Demografía y Asistencia Social, Año 1936; 1931-1949, INE, Demografía y Asistencia Social, Año 1950.

4. INE, Anuario de Estadísticas Vitales, serie 1950-2009.

14. La migración neta, derivada de la diferencia entre la población inmigrante y la emigrante a un territorio en un período dado, también es un componente de los cambios demográficos. En consecuencia, el crecimiento total de una población está formado por el crecimiento natural y el saldo migratorio neto. Sin embargo, en el caso de Chile, este último componente ha tenido menor relevancia, por lo que, para simplificar la exposición, no se considerará en este análisis. 
Se hará referencia a la evolución del crecimiento natural de la población (natalidad menos mortalidad) durante el período previo a la transición, hasta 1932, y a la transición demográfica, iniciada en 1933.

Entre 1900 y 1930 la natalidad osciló a alrededor de 40 nacimientos por cada mil personas. La mortalidad tuvo oscilaciones hasta la década de $1920^{15}$, a partir de la cual comienza un sostenido descenso, llegando hacia el año 1930 a alrededor de 25 muertes promedio por cada mil habitantes. Hasta aproximadamente 1932 la tasa de mortalidad presentó oscilaciones fuertes debido a situaciones efectivas por una parte y, por otra, a la existencia de una cultura básica de cuidado de la salud francamente deficiente de parte de la población, además de que aún no existía un ministerio encargado de las políticas de salud.

En 1933 se puede considerar que en Chile comenzó la primera fase de la transición demográfica, primero con un descenso de la mortalidad, desde 27 a 12 defunciones por mil habitantes aproximadamente entre 1933 y 1961, respectivamente. En tanto, la natalidad se mantuvo en valores alrededor de 30-32 por mil de 1933 a 1954, luego se incrementó entre 1955 y 1961 de 32 a 35 nacimientos por cada mil habitantes. Este período (1933-1961) fue el de mayor crecimiento natural o vegetativo, lo que contribuyó también al mayor ritmo de crecimiento promedio anual de la población, esto es, de 2,5 habitantes promedio anual entre 1952 y 1960.

En resumen, en el período 1930-1960 el descenso en la tasa de mortalidad llegó a menos de 15 muertes por cada mil habitantes, y se observó una relativa estabilidad de la natalidad.

Después de 1961 comenzó la fase avanzada de la transición demográfica, caracterizada por la continuidad de la baja de la mortalidad y el inicio sostenido del descenso de la natalidad, encontrándose actualmente el país en esta etapa. La natalidad inicia este período con más de 35 nacimientos por cada mil habitantes, oscila en torno a 23 en los años 80 y 90, luego continúa su descenso y llega al año 2006 con valores cercanos a 14 nacimientos por cada mil habitantes. Hacia los años 80 la mortalidad infantil ya había alcanzado niveles bastante bajos, por lo tanto la disminución de la tasa de mortalidad se hizo más lenta, centrándose el riesgo de muerte en las poblaciones de edades más avanzadas.

Esta evolución desde niveles altos a bajos de la mortalidad y de la natalidad, ocurridos con mayor intensidad desde los años 60 , da cuenta del proceso de transición demográfica avanzada en que se encuentra Chile, situación similar a la de otros países de la región latinoamericana, como Argentina, Brasil y Costa Rica, que comienza a asemejarse al panorama demográfico en el que ya están los países desarrollados desde algunas décadas atrás, es decir, en proceso de una nueva transición demográfica o finalizando la fase anterior del envejecimiento demográfico de su población.

15. El fuerte aumento de la mortalidad en 1918-1920 se debió a dos epidemias de influenza, que afectaron con mayor intensidad a las personas adultas, en edades avanzadas y a los menores de 15 años (Laval, 2003). 
Como una porfiada muestra de la realidad, en Chile se estarían dando, simultáneamente a la fase descrita de la transición demográfica clásica, algunos factores que caracterizan o acompañan a la segunda transición demográfica (término creado por Lesthaeghe y van de Kaa, 1986). Sin entrar en detalles, se puede mencionar que en Chile se dan, desde alrededor de los últimos veinte años: el aumento de los nacimientos fuera del matrimonio, el incremento porcentual de la convivencia, el retraso en la edad al matrimonio y a la primera unión de hecho, el retraso del primer hijo y también del segundo, surgimiento de nuevos tipos de familias, entre otros aspectos.

Tratando de evaluar un posible escenario futuro del crecimiento natural de la población en Chile, respecto de los valores de los países desarrollados de la Organización para la Cooperación y Desarrollo Económico (OCDE) -varios de los cuales se encuentran en la denominada cuarta fase de la transición, esto es, con un crecimiento natural muy bajo o cercano al estancamiento-, vale decir que la natalidad en Chile es aún alrededor de un 30\% superior a la de esos países y la mortalidad un 30\% inferior. Así, según las proyecciones de población del país, desde aproximadamente el año 2040 el crecimiento natural sería de 0,8 por mil habitantes promedio anual y de 0,1 por mil habitantes hacia mediados del siglo XXI (INE, 2005).

\section{¿CUÁL HA SIDO LA EVOLUCIÓN DE LOS COMPONENTES DEMOGRÁFICOS DEL CRECIMIENTO DE LA POBLACIÓN EN CHILE DESDE 1950 A LA ACTUALIDAD?}

El efecto conjunto de las transiciones socioeconómica y epidemiológica, insertas en las transformaciones sociales, económicas y culturales en Chile durante el siglo XX y con mayor intensidad desde la segunda mitad, y que se mantienen en el presente siglo, han incidido primero en el descenso, a través del tiempo, de la mortalidad y de la natalidad, y luego en las modificaciones de la estructura por edades de la población. La tendencia es a la baja del aporte porcentual de los menores de 15 años y al aumento del porcentaje de personas de 60 años o más (adultos mayores).

Los componentes demográficos del crecimiento de la población son afectados por las dimensiones socioeconómica y epidemiológica, lo cual se presenta en el Cuadro 3. Desde 1950 el ritmo promedio del crecimiento total de la población tiende a disminuir. El mayor aporte a dicho incremento proviene del crecimiento natural o vegetativo, el cual, a su vez, tiende a disminuir. Por su parte, la migración internacional ha sido negativa y en disminución, para alcanzar valor positivo entre 2010 y $2015^{16}$.

16. De acuerdo a la proyección de población nacional elaborada con los datos demográficos observados hasta el año 2002, la tasa de migración neta internacional del período 1950-1990 fue negativa; a partir de 1990-2000 se transformó en positiva. La hipótesis de evolución futura, a partir del 2000, supuso que sería positiva y con tendencia a disminuir hasta aproximadamente el 2020, luego de lo cual se mantendría nula hasta mediados del presente siglo (véase Informe metodológico y de resultados de la proyección de población nacional 1950-2050, "Chile: Proyecciones y Estimaciones de Población. Total País: 1990-2050", 2005). 
En términos porcentuales, el crecimiento natural aporta la mayor parte del crecimiento total, representando en la actualidad alrededor del 98\% del crecimiento promedio de la población del país.

Estudiando el cambio porcentual del ritmo de crecimiento de los componentes demográficos, a lo largo de los 65 años del período 1950-2015, tanto el crecimiento total como los componentes experimentarían el mayor cambio porcentual de su tasa en el segundo período, entre 1983 y 2015. No obstante, debe mencionarse que, mientras en este último período el crecimiento natural disminuiría alrededor de un 49\% su ritmo promedio, el cambio porcentual de la tasa de migración neta internacional sería más relevante por cuanto pasó de emigración a inmigración.

En otras palabras, respecto del período 1950-1983, entre 1983 y 2015 el ritmo de aumento del crecimiento natural descendería a la mitad; en cambio, el de la migración neta internacional se duplicaría.

\section{Cuadro 3}

RITMO DE CRECIMIENTO, DISTRIBUCIÓN Y CAMBIO PORCENTUAL DE LA POBLACIÓN, SEGÚN COMPONENTES DEMOGRÁFICOS. 1950-2015

\begin{tabular}{|c|c|c|c|}
\hline Componente (1) & $1950-1955$ & 1980-1985 & $2010-2015$ \\
\hline \multicolumn{4}{|c|}{ Tasa de crecimiento de la población (por mil personas) } \\
\hline TCT & 21,3 & 16,0 & 8,8 \\
\hline TCN & 22,5 & 17,0 & 8,6 \\
\hline TMN & $-1,2$ & $-1,0$ & 0,2 \\
\hline \multicolumn{4}{|c|}{ Distribución porcentual } \\
\hline TCT & 100,0 & 100,0 & 100,0 \\
\hline TCN & 105,6 & 106,3 & 97,7 \\
\hline TMN & $-5,6$ & $-6,3$ & 2,3 \\
\hline
\end{tabular}

\section{Cambio porcentual del ritmo de crecimiento}

\begin{tabular}{|c|c|c|}
\hline Componente (1) & $1950-1983$ & $1983-2015$ \\
\hline TCT & 24,9 & 45,0 \\
\hline TCN & 24,4 & 49,4 \\
\hline TMN & 16,7 & 120,0 \\
\hline
\end{tabular}

Fuente: CELADE-División de Población CEPAL, Boletín Demográfico 73, América Latina y El Caribe: Estimaciones y Proyecciones de Población. 1950, Enero 2004, Santiago de Chile.

(1) TCT: Tasa de crecimiento de la población, promedio anual; TCN: Tasa de crecimiento natural o vegetativo, promedio anual; TMN: Tasa de migración neta internacional, promedio anual.

En la sección anterior se mencionó que en la región latinoamericana, Chile, junto a Argentina, Brasil y Costa Rica, se encuentran en una etapa avanzada hacia el envejecimiento demográfico de su población. En el Cuadro 4 puede observarse que los cuatro países disminuyen el ritmo de crecimiento medio anual en el tiempo (Tasa de Crecimiento Promedio Anual, TCPA), y que además disminuye la brecha entre ellos en 
cuanto a la rapidez del crecimiento de la población de cada país. Ya hacia el 2015 Chile tendría el menor ritmo de crecimiento medio anual poblacional entre los cuatro países.

\section{Cuadro 4}

PAÍSES SELECCIONADOS: RITMO DE CRECIMIENTO DE LA POBLACIÓN. 1950-2015

\begin{tabular}{|l|c|c|c|}
\hline \multirow{2}{*}{ País } & \multicolumn{3}{|c|}{ TCPA (por mil personas) } \\
\cline { 2 - 4 } & $1950-1955$ & $1980-1985$ & $2010-2015$ \\
\hline Chile & 21,3 & 16,0 & 8,8 \\
\hline Argentina & 19,7 & 15,2 & 9,5 \\
\hline Brasil & 30,6 & 22,5 & 11,1 \\
\hline Costa Rica & 31,2 & 27,8 & 13,5 \\
\hline
\end{tabular}

Fuente: CELADE-División de Población CEPAL, Boletín Demográfico 73, América Latina y El Caribe: Estimaciones y Proyecciones de Población. 1950-2050, Enero 2004, Santiago de Chile.

No obstante que en Latinoamérica, Chile, Argentina, Brasil y Costa Rica comparten la transición avanzada en el envejecimiento demográfico de su población, no son los más envejecidos. Así, en la región, Uruguay y Cuba son los dos países que llevan la delantera, por cuanto ambos están transitando a una fase muy avanzada del envejecimiento demográfico de su población.

\section{ALGUNOS EFECTOS SOBRE LA ESTRUCTURA DE LA POBLACIÓN}

Según lo antes citado, el proceso de envejecimiento demográfico de la población se debe al efecto directo de los cambios en los componentes demográficos, en especial, debido al descenso preferente de la mortalidad y de la fecundidad, esta última con mayor impacto. A su vez, los cambios experimentados por estos dos componentes demográficos se deben, por una parte, a la transición socioeconómica y, por otra, a la transición epidemiológica.

El descenso de la fecundidad, la baja en la mortalidad y el aumento en la esperanza de vida han provocado cambios en la estructura por sexo y edad de la población. Esto implica que se está produciendo una disminución del porcentaje de población joven y un aumento de la población en las edades adultas y más avanzadas, tendencias que en las próximas décadas se mantendrían y que luego se acelerarían.

Esta tendencia, prácticamente, invertiría la actual relación que existe entre los dos grupos de edad extremos. De este modo, se estima que para el año 2012 habría 63 adultos mayores por cada 100 menores de 15 años ( 1 adulto mayor por cada 1,6 menores de 15 años), igualándose ambos grupos aproximadamente en el año 2024. A mediados del presente siglo, en Chile habría 170 adultos mayores por cada cien menores de 15 años, es decir, en el año 2050 habría 1,7 adultos mayores por cada infante.

Por otro lado, el grupo potencialmente activo (personas de 15 a 59 años de edad) presentaría una disminución de diez puntos porcentuales de su aporte relativo entre el 
2011 y 2050, de 65\% a 55\%, respectivamente. Cabe resaltar que este indicador aumentó entre 1965 y 2010, provocado por el aporte de personas que nacieron en dos generaciones con características opuestas de fecundidad: la primera, de 1950 a 1961, época de fecundidad en ascenso, y la segunda, de 1961 a 1995, de fecundidad en descenso. El período siguiente, de descenso de la proporción de la población potencialmente activa a partir de 2011, está conformado por las personas nacidas en períodos de baja fecundidad.

Cabe resaltar que la estructura poblacional de Chile a mediados del siglo XX era muy diferente a la del 2000 y de la esperada para 2050. La de 1950 se caracterizaba por una población preponderantemente joven, con una base expandida disminuyendo rápidamente hacia los grupos de edad más avanzados. La evolución de la estructura poblacional de Chile se observa en el Gráfico 6, que muestra tres momentos representativos de la historia demográfica reciente y esperada de nuestro país: el primero referente al momento previo al inicio del envejecimiento demográfico (1950), el segundo correspondiente a la etapa en transición avanzada (2000) y el tercero relativo a una población en transición muy avanzada al envejecimiento (2050).

\section{Gráfico 6}

DISTRIBUCIÓN DE LA POBLACIÓN POR SEXO Y EDAD.

PROYECCIONES DE POBLACIÓN. 1950-2050

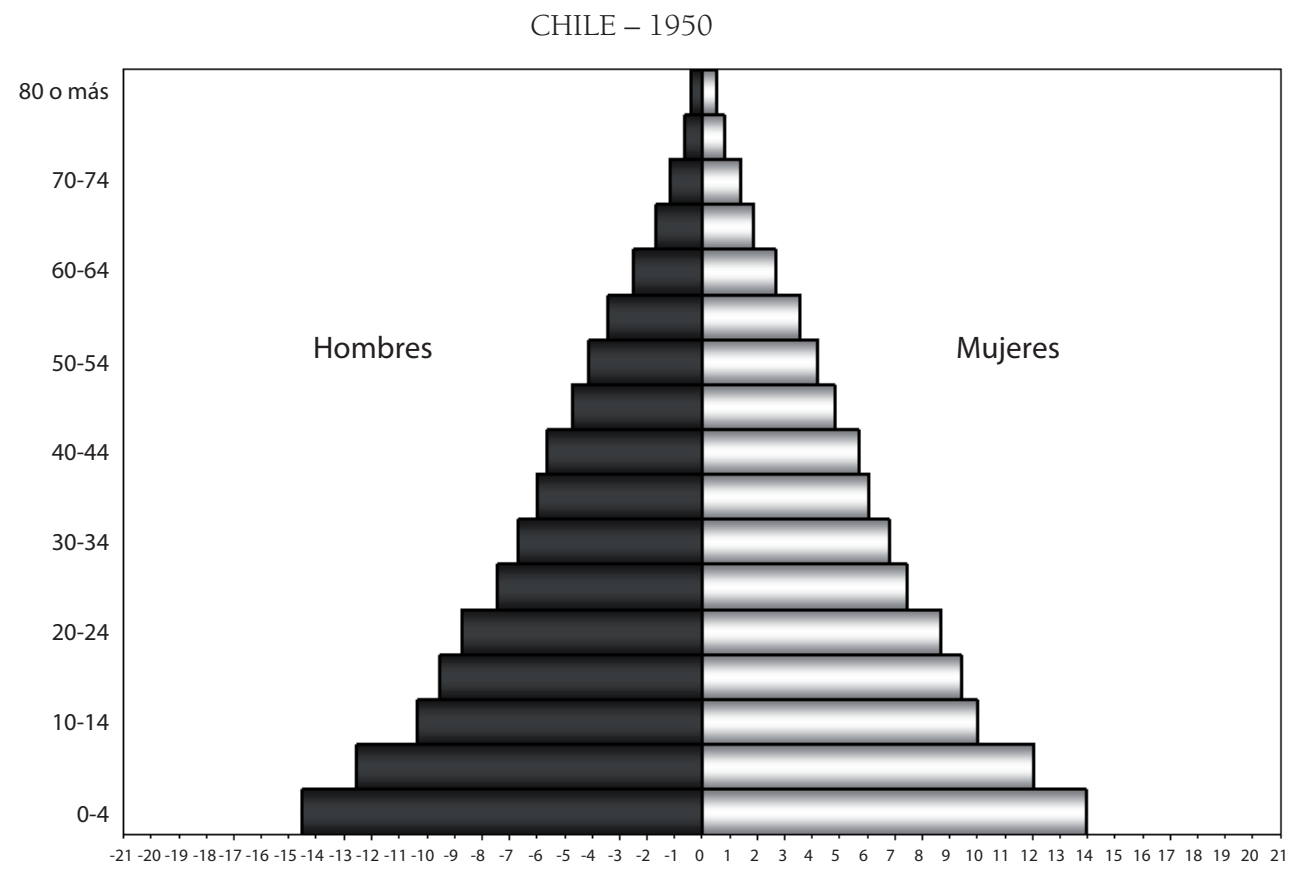


CHILE - 2000

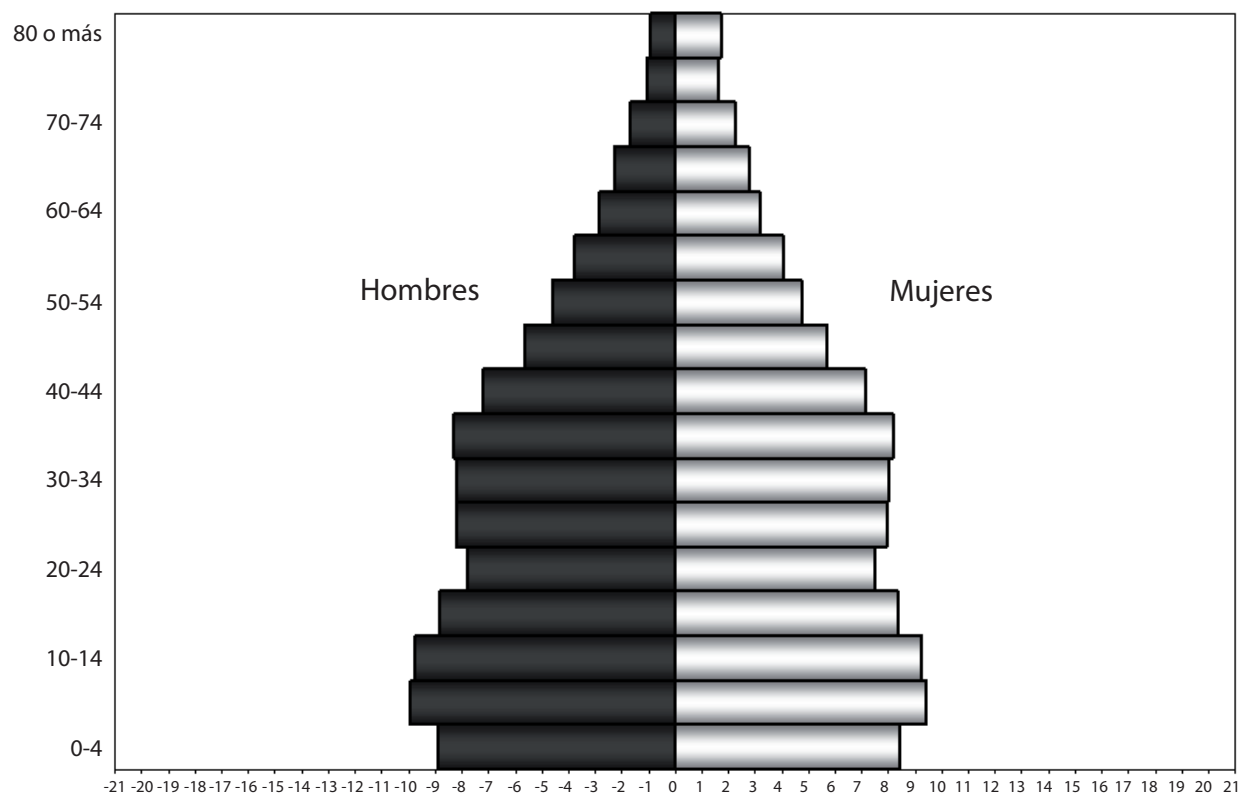

CHILE - 2050

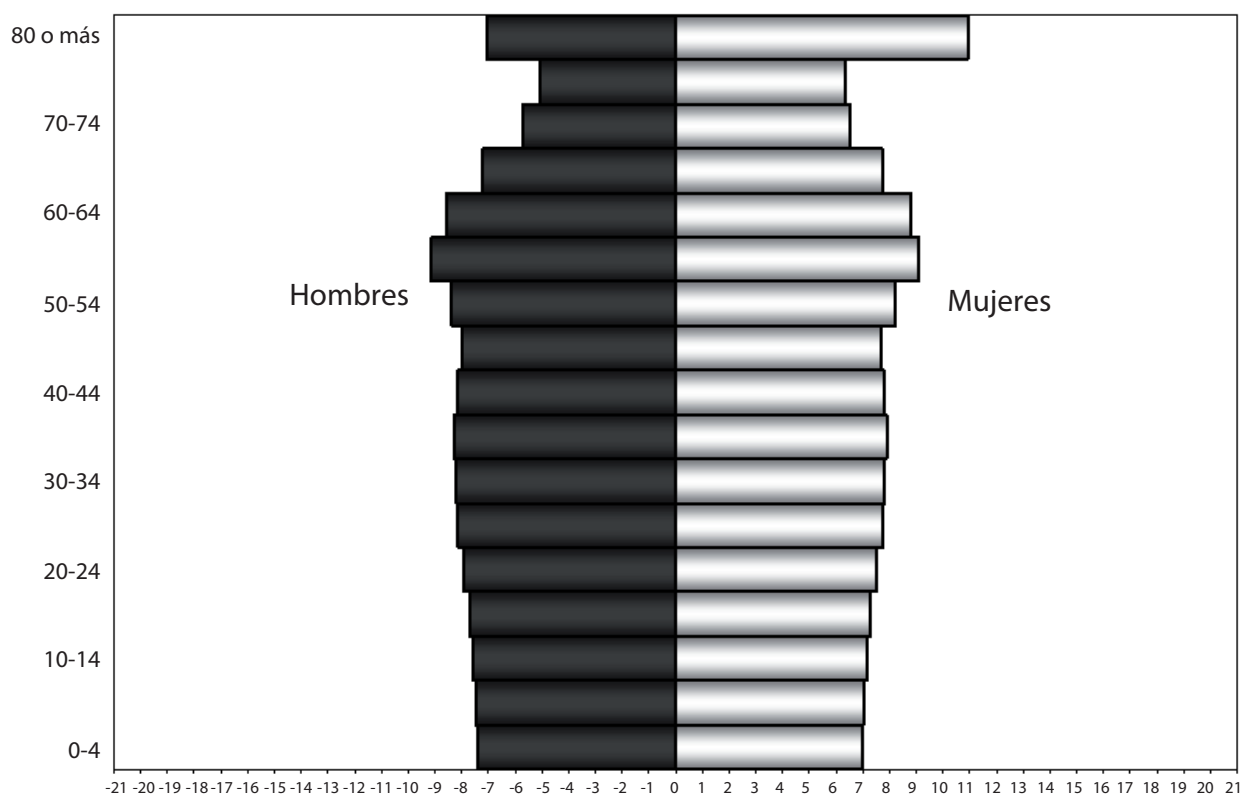

Fuente: INE, elaborado a partir de las Proyecciones de Población, País 1950-2050. 
Siendo relevante el rol de la fecundidad y de la mortalidad en las modificaciones de la estructura de la población por sexo y edad, debido al efecto de factores tanto socioeconómicos como epidemiológicos, se analiza a continuación cada uno de estos preponderantes componentes demográficos.

\section{CAMBIOS DE LA FECUNDIDAD}

La fecundidad es el estudio de la frecuencia de los nacimientos vivos aportados por las mujeres en edad fértil, esto es, entre los 15 y 49 años (INE, 2006). La fecundidad se analizará a través de la tasa global de fecundidad (TGF), cuyo nivel expresa el número promedio de hijas e hijos nacidos vivos que aporta cada mujer que ha concluido su período fértil y que sobrevivió hasta el término de este.

Durante el período 1950-1960 aproximadamente, la fecundidad varió de 4,6 a 5,4 hijas e hijos promedio por mujer. En 1961 la fecundidad alcanzó el mayor nivel de la serie descrita: 5,43 hijas e hijos promedio por mujer (Gráfico 7). Desde esa fecha en adelante, y hasta 1979 (en que alcanzó a 2,7 hijas e hijos promedio), se produjo una significativa baja de este indicador, lo que porcentualmente implicó un descenso del 50\% en el nivel de fecundidad en tan solo 18 años (1961-1979). Posteriormente esta baja fue más lenta pero sostenida, alcanzando entre 1999-2000 valores muy cercanos a 2,1 hijas e hijos por cada mujer, valor considerado de reemplazo generacional ${ }^{17}$. La tendencia de la fecundidad en el último decenio ha sido de baja hasta el 2006, luego de lo cual ha tenido un leve aumento entre 2007 y 2009, siempre bajo el nivel de reemplazo. La tendencia proyectada de la fecundidad, más allá del 2009, es al descenso, hasta alcanzar 1,85 hijas e hijos por mujer hacia el 2020, situación que se mantendría hasta mediados del presente siglo (INE, 2005).

17. El valor de la tasa global de fecundidad de 2,1 hijas e hijos promedio por cada mujer, es considerado un valor de reemplazo generacional de la madre y del padre, por cuanto dicho valor se desglosa por sexo, así: 1 hija y 1,1 hijos en promedio. Francia, Cuba, Japón, Alemania, España, son algunos países con fecundidad deficitaria (inferior al nivel de reemplazo generacional). Tienen valores inferiores a la fecundidad de las mujeres de Chile. El 2009, el nivel de fecundidad de las mujeres de Chile fue de 1,94 hijas e hijos promedio por cada mujer. 


\section{Gráfico 7}

TASA GLOBAL DE FECUNDIDAD. 1950-2009

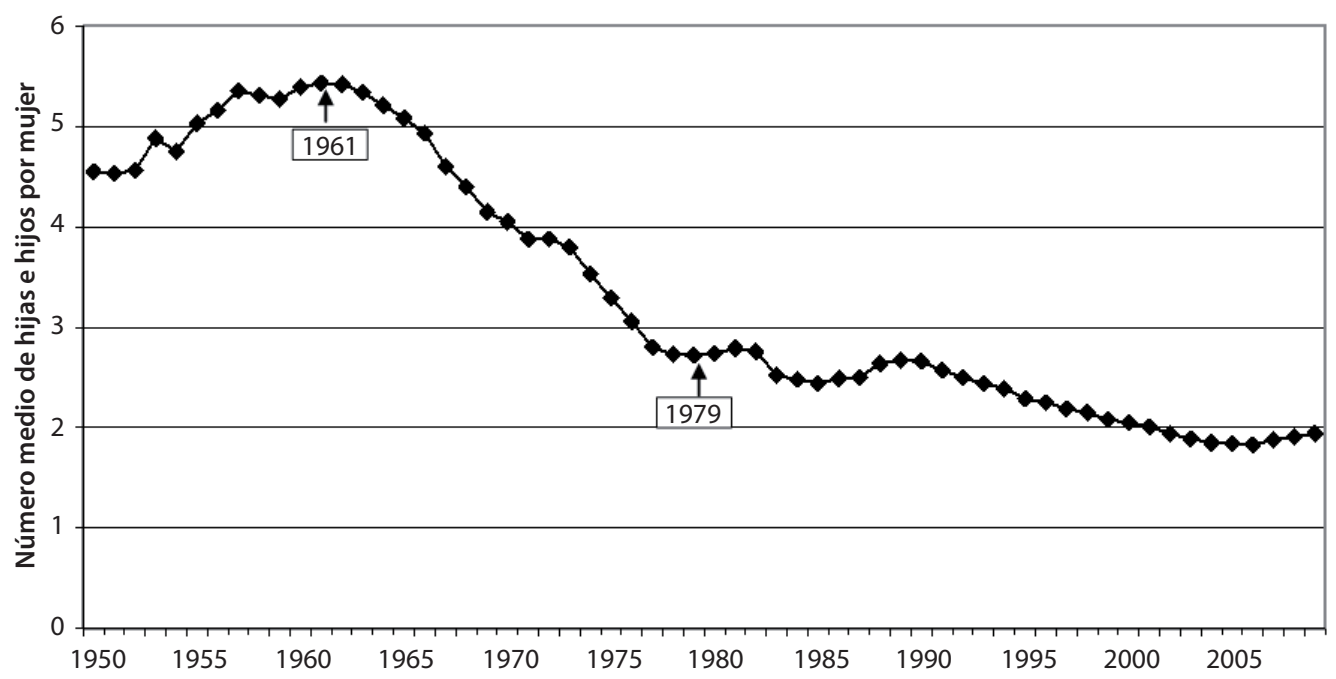

Fuente: INE, elaborado a partir de las Estadísticas Vitales y las Proyecciones de Población Nacional de 1950 a 2009 .

\section{DESCENSO DE LA FECUNDIDAD POR EDAD}

La fecundidad está estrechamente relacionada con la edad media de las madres. El período fértil de las mujeres se estima entre los 15 y 49 años, es decir, la totalidad de nacimientos ocurren en un lapso de 35 años. Sin embargo, al interior de este período se producen tasas significativamente diferentes de fecundidad. En la actualidad, los 28 años es la edad media en la cual las mujeres son madres, lo que no ha cambiado mucho en el tiempo.

Se presenta a continuación el Gráfico 8, con la fecundidad por edad de la madre, destacando los años inicial y final de la serie, así como también el año de la mayor fecundidad y el correspondiente a 1979, momento en que la fecundidad descendió un $50 \%$ desde 1961.

El impacto, debido al descenso entre 1961 y 1979 a la mitad de la fecundidad total en tan solo 18 años, sobre la composición de la población por sexo y edad, ha contribuido al envejecimiento demográfico de la población. Esta baja de la fecundidad también incide en el descenso porcentual de los menores de 15 años, por la baja de los nacimientos.

En cambio, entre 1979 y 2009, en 30 años, el descenso de la fecundidad total fue de 2,7 a 1,9 hijas e hijos promedio por cada mujer, lo que representa solo un $29 \%$ de baja en tres décadas. 


\section{Gráfico 8}

TASAS ESPECÍFICAS DE FECUNDIDAD, POR GRUPOS DE EDAD

DE LA MADRE. 1950, 1961, 1979 Y 2009

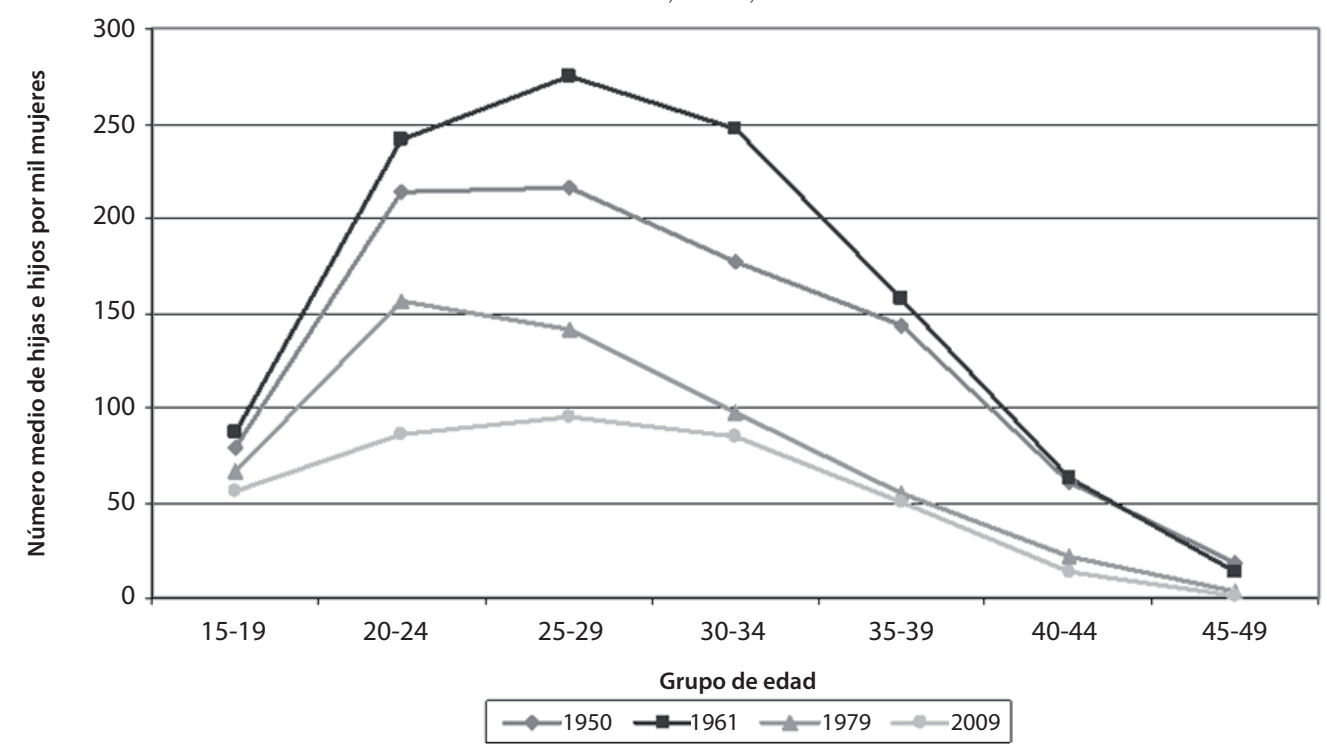

Fuente: INE, elaborado a partir de las Estadísticas Vitales y las Proyecciones de Población Nacional de 1950 a 2009.

Del Gráfico 8 se observa el aumento de la fecundidad específica entre 1950 y 1961 , sobre todo entre los 20-39 años. Luego de 1961 se aprecia la baja considerable por edades. Por ejemplo, en 1961 las mujeres más fecundas eran las de 25-29 años y aportaban 274 hijas e hijos por cada mil mujeres de esa edad. En cambio, el 2009 las mujeres de esa cohorte aportaron tan solo 96 hijas e hijos por cada mil mujeres.

El impacto de la baja de la fecundidad entre 1961 y 1979 fue inferior al 50\% en las mujeres menores de 30 años, en tanto que en las de 30 años o más fue de por lo menos 60\%. En cambio, entre 1979 y 2009 la fecundidad total descendió un 29\%. Por edades fue más importante la baja en los 20-24 años, con un 45\%, a los 40-44 años con un 36\% y a los 45-49 años, con un $80 \%$.

Los significativos cambios ocurridos en la fecundidad chilena están ligados a factores demográficos y socioeconómicos como, por ejemplo, la voluntad de las parejas de restringir el tamaño de su familia, el aumento del espaciamiento de los hijos, el incremento de la urbanización, el retraso de la edad de la primera unión o matrimonio, el aumento del nivel educacional femenino, la incorporación de la mujer a la fuerza de trabajo, el mayor conocimiento y uso de métodos anticonceptivos, entre otros. Estos cambios reflejan las diferencias especificas de los diversos grupos de edad, puesto que permiten observar variaciones en un conjunto de prácticas de diverso orden, como por ejemplo el ámbito laboral, o según el acceso que tienen a diversos recursos, como los medios 
materiales y de información que permiten la planificación familiar y a los que, dicho sea de paso, no acceden con facilidad, como es el caso de parte de las adolescentes.

Las consecuencias del descenso en la fecundidad sobre el tamaño y composición de las familias son evidentes. De un promedio superior a los 5 hijos por mujer en la década de los 50 , se ha llegado a un promedio de menos de 2 hijos e hijas promedio por familia. Este solo cambio provocó un inmenso impacto en la estructura de los hogares y en los roles de quienes los componen; incluso solamente considerando un modelo de familia "tradicional", hay consecuencias, por ejemplo, sobre los modelos de crianza de los niños - desde niños que se criaban junto a varios hermanos, a niños que tienen uno o ningún hermano-, o sobre las posibilidades de las mujeres de destinar mayor tiempo a actividades distintas al cuidado de sus hijos, como el trabajo.

\section{CAMBIOS DE LA MORTALIDAD}

Como se analizó en la sección de la transición epidemiológica, entre 1950 y 2009 se produjo un cambio en la estructura de las defunciones por edad desde una alta concentración porcentual en edades infantiles y jóvenes a mediados del siglo pasado, hacia una concentración de muertes en edades avanzadas en 2009. Por causas de muerte, en 1950 predominaban aquellas infecciosas y parasitarias que afectaban preferentemente al sector infantil. En cambio, en 2009, se traslada la mayor preponderancia porcentual de las causas de muerte hacia los tumores malignos y enfermedades del sistema circulatorio, enfermedades de carácter degenerativo que inciden principalmente sobre la salud de los adultos mayores y de las personas de edades más avanzadas.

De este modo, se confirma que el importante descenso experimentado por la mortalidad es el resultado conjunto de una mayor y mejor cobertura de los servicios de salud, de las mejoras y adelantos tecnológicos, del desarrollo de la medicina, así como también de las mejores condiciones socioeconómicas y culturales de la población, entre otras causas.

De los gráficos a continuación, que representan las tasas centrales de mortalidad por sexo y edades, se desprende que tanto en 1950 como en 2009, la mortalidad específica por grupos de edad femeninos es inferior a la masculina.

Analizando al interior de cada sexo, en los hombres entre 1950 y 2009 se produjo un mayor descenso de las tasas entre los 5 y los 50 años. En el caso femenino, el descenso se manifestó principalmente entre los 5 y 64 años.

Cabe hacer presente, en el caso masculino, que tanto en 1950 como en 2009 se manifiesta un incremento de la mortalidad entre los 15 y los 34 años, algo más pronunciado en el 2009 que en 1950. En el caso femenino es muy leve el aumento entre 15-19 años. Este mayor impacto de la mortalidad en edades jóvenes masculinas que femeninas, se debería principalmente a muertes por causas externas. 
Gráfico 9A

TASAS CENTRALES DE MORTALIDAD - HOMBRES. 1950 - 2009

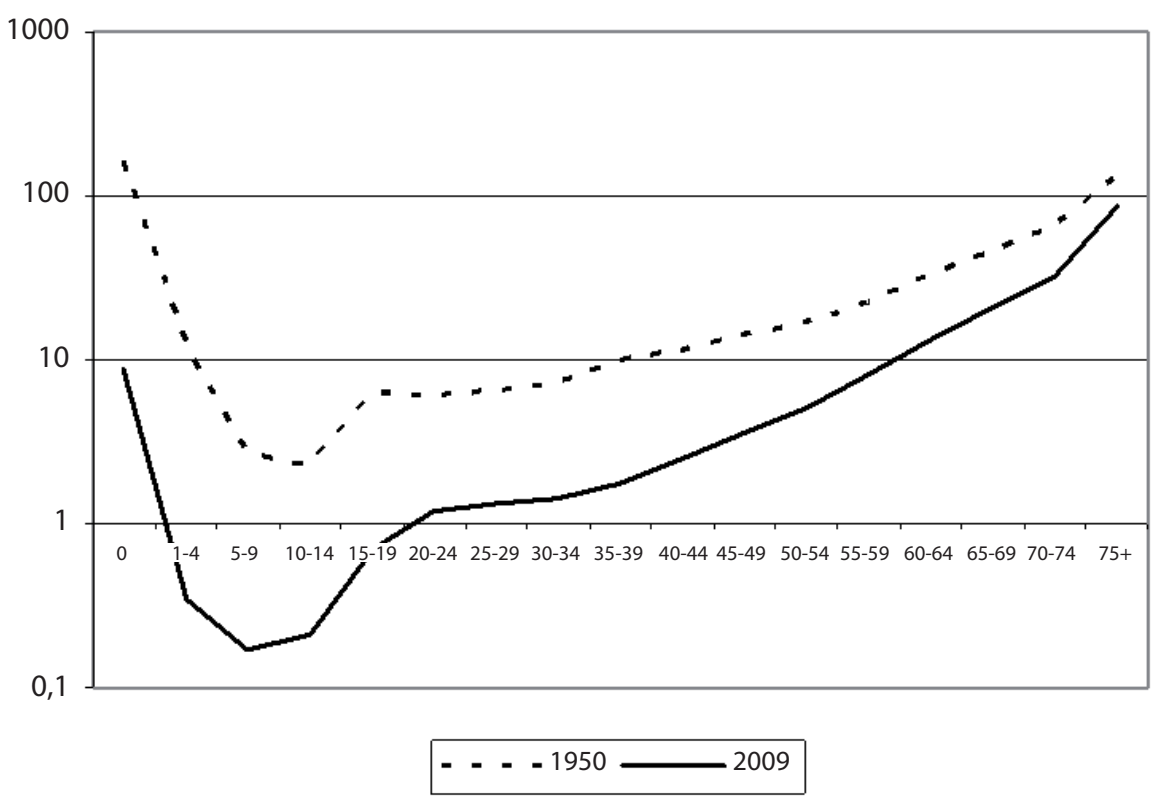

Gráfico 9B

TASAS CENTRALES DE MORTALIDAD - MUJERES. 1950 - 2009

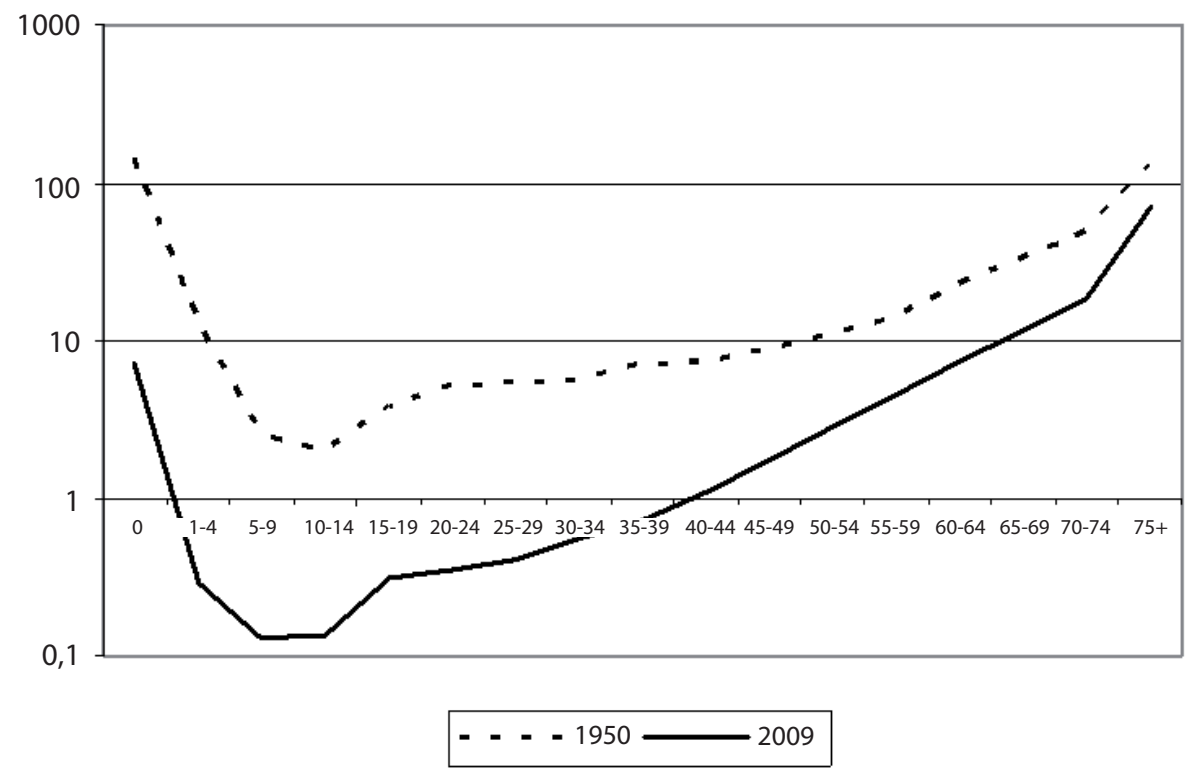

Fuente: INE, elaborado a partir de las Estadísticas Vitales y las Proyecciones de Población Nacional de 1950 y 2009. 
Ya analizada la estructura de la mortalidad por sexo y edades, a través de las tasas centrales de mortalidad, corresponde estudiar el nivel de mortalidad, el cual se representa a través de la esperanza de vida al nacer, que expresa el número medio de años que, se espera, pueda vivir un(a) recién nacido(a), en cierto territorio y período.

Un recién nacido en Chile, en 1950, podía esperar vivir en promedio 55 años (53 un niño y 57 una niña) ${ }^{18}$. En 1980 vivía en promedio 71 años (67 un niño y 74 una niña). En 2012 podría vivir en promedio 79 años (76 un niño y 81 una niña). Nótese la mayor ganancia absoluta entre 1950-1980 que entre 1980-2010. Además, el diferencial de esperanza de vida al nacer favorece a la mujer y se incrementó de 4 años en 1950 a 5 en 2012.

\section{Gráfico 10}

ESPERANZA DE VIDA AL NACER, POR SEXO. 1950-2015

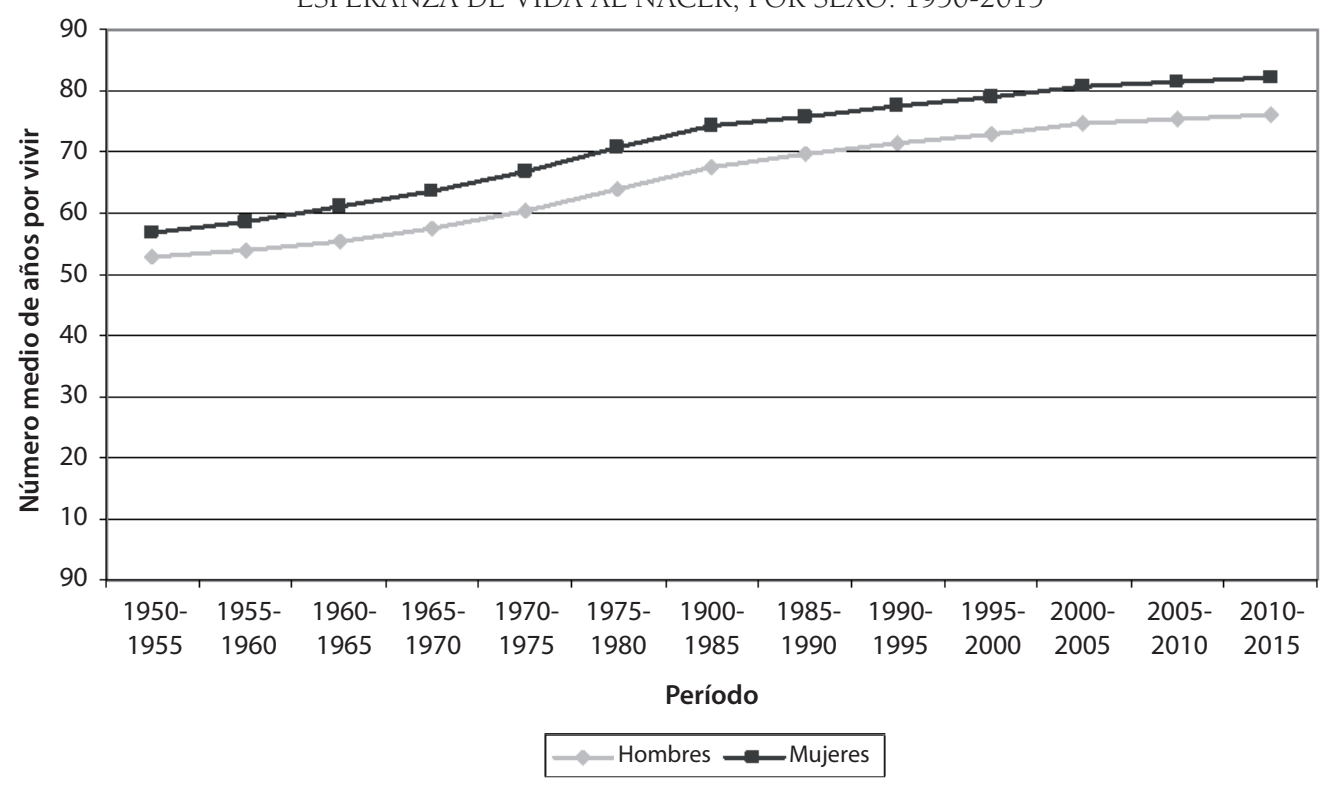

Fuente: INE, elaborado a partir de las Proyecciones y Estimaciones de Población, País 1950-2050.

Del gráfico se aprecia que la tendencia a través de los 65 años es ascendente en hombres y mujeres, siendo regular el diferencial por sexo favorable a la mujer recién nacida durante la serie. La mayor pendiente de las curvas masculina y femenina en la primera mitad de la serie confirma lo comentado anteriormente, en cuanto a las mayores ganancias del indicador en este período.

También resulta de interés estudiar el cambio de esperanza de vida de la población a la edad de 60 años. Ciertamente, a esta edad las mejoras en el tiempo en esperanza de

18. Es interesante mencionar que a inicios del siglo XX, en Chile, la esperanza de vida al nacer no superaba los 30 años. 
vida son inferiores que al nacimiento o a edades menores de 60 años. Sin embargo, tanto las mujeres como los hombres de esa edad ganaron en promedio 4 años de esperanza de vida, entre 1980 y 2012 (hombres de 17 a 21, mujeres de 20 a 24 años de esperanza de vida). En cambio, entre 1950 y 1980 los hombres ganaron en promedio 2 años y las mujeres 3 (hombres de 15 a 17, mujeres de 17 a 20 años de esperanza de vida).

\section{EFECTOS Y DESAFÍOS}

\section{EN RESUMEN: ¿CUÁL ES EL ESCENARIO DEMOGRÁFICO EN CHILE?}

Desde los años 60 el país está creciendo; en términos poblacionales a un ritmo promedio anual cada vez menor, de acuerdo a como lo indican los censos de población (ver Cuadro 1), acompañado de una fecundidad por debajo del nivel de reemplazo desde el año 2000 (inferior a 2,1 hijas/hijos por mujer). A este escenario se agrega la disminución considerable de la población de 15 años o menos, la cual de 1950 a 2012 ha pasado en términos relativos de $37 \%$ a $22 \%$. Por el contrario ha aumentado considerablemente la importancia relativa de la población adulta mayor, siendo esta de 7\% en 1950 y de 14\% en 2012. Esto implica que mientras la población infantil en los últimos 60 años ha disminuido su importancia relativa en aproximadamente $41 \%$, la adulta mayor se ha duplicado en el mismo intervalo de tiempo.

Todas estas estadísticas e indicadores nos muestran que Chile está avanzando rápidamente hacia un envejecimiento demográfico, y así lo demuestra nuestra esperanza de vida al nacer, que en los años 50 era de 53 años para los hombres y 57 años para las mujeres, aproximadamente, mientras que hoy es de 76 y 81 años, para hombres y mujeres respectivamente.

\section{¿CUÁLES SON LAS CONSECUENCIAS DEL ENVEJECIMIENTO DEMOGRÁFICO EN LA SOCIEDAD?}

Para responder esta pregunta se recurre al Índice de Dependencia Demográfica (IDD), que corresponde al cuociente entre la población potencialmente inactiva (menores de 15 años y personas de 60 años o más) y la población potencialmente activa (personas entre 15 y 59 años de edad). Expresa la carga económica que la población potencialmente activa (PPA) debe sustentar. Un escenario positivo es cuando el indicador va en descenso (menor que 1 o menor que 100) pues indica que la carga a sustentar es cada vez menor; el problema se sitúa cuando la curva del índice se invierte y esta carga comienza a subir.

Este indicador tiene importancia para el desarrollo sostenible, y en especial en nuestro país, donde se observa un envejecimiento avanzado de la población. Una dependencia demográfica alta aumenta la necesidad de ingresos de la población potencialmente activa para que la población inactiva pueda mantener su calidad de vida. 
Por un lado tenemos que la gente vive más años; por otro, que el contingente de adultos mayores es cada vez mayor. El IDD cambió su tendencia aproximadamente en 2011 y se estima que para el año 2050 sería de 81 inactivos por cada 100 personas potencialmente activas. Así, en la situación más extrema, nos aproximamos a una población envejecida demográficamente, cuantitativamente grande, viviendo muchos más años de vida, esto es, muchos jubilados siendo sostenidos, en términos demográficos, por una pequeña población potencialmente activa ${ }^{19}$.

\section{Gráfico 11}

ÍNDICE DE DEPENDENCIA DEMOGRÁFICA. 1950-2050

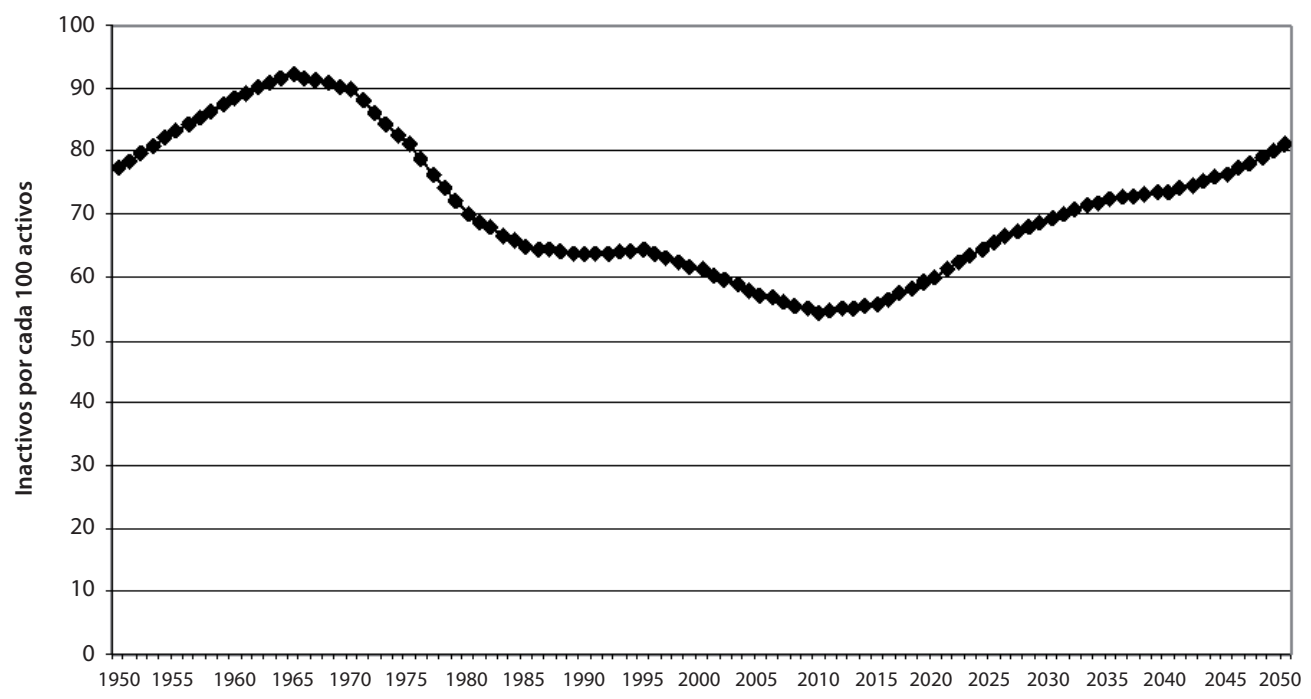

Fuente: INE, Proyecciones y Estimaciones de Población, País 1950-2050.

El proceso de envejecimiento demográfico avanzado exige al país estar preparado para grandes cambios a nivel económico, cultural y social. Mientras el país mantenga una dependencia demográfica baja, es decir, mientras mayor sea el grupo de personas potencialmente activas, Chile estará en una situación ventajosa, pues implica menos exigencias para los sistemas de salud materno-infantil y de educación escolar (debido a la tendencia decreciente de la población menor de 15 años de edad). Esto trae ventajas para el desarrollo del país pues permite reorientar sus recursos hacia la inversión social, la salud y la lucha contra la pobreza (CELADE, 2005) y, además, prepararse para las futuras demandas de la población adulta mayor, que en el 2050 será de 5,7 millones de personas, esto es, un $28 \%$ de la población total.

19. Recuérdese que el porcentaje de población potencialmente activa descendería entre 2011 y 2050, de $65 \%$ a $55 \%$ del total (véase sección "Algunos efectos sobre la estructura de la población"). 
Este período de holgura, hoy en disminución, es denominado bono demográfico, del cual el país tiene que sacar provecho y prepararse para los períodos más difíciles. Esto implica que el Estado y la sociedad tienen el desafío conjunto de crear e implementar políticas sociales que generen las condiciones necesarias, en un tiempo limitado, puesto que la bonanza demográfica está en reducción, a fin de mejorar las condiciones socioeconómicas que contribuyan al desarrollo de nuestro país.

\section{REFERENCIAS BIBLIOGRÁFICAS}

Arriaga, E., El análisis de la población con microcomputadoras, Doctorado en Demografía, Facultad de Ciencias Económicas, Universidad Nacional de Córdoba, Argentina, Editorial Copiar, 2001.

Ffrench-Davis, R., "Crecimiento en desigualdad: las dos caras de Chile", en Revista Occidente, $\mathrm{N}^{\circ}$ 408, 8: 19, 2011.

CELADE, División de Población de la CEPAL, "Transición Demográfica. Cambios en la estructura poblacional: Una pirámide que exige nuevas miradas" en Temas de Población y Desarrollo, (1), 2005.

INE, Censo de Población 1907, [1908].

— Censo de Población 1952, [1956].

— Censo de Población 1960, Resumen País, [1960].

- Chile: Proyecciones y Estimaciones de Población. Total País: 1990-2050, véase online en http://www.ine.cl/canales/chile_estadistico/demografia_y_vitales/demo_y_vita.php, 2005.

— Chile: Proyecciones y Estimaciones de Población. Total País: 1990-2050. País y Regiones Urbano-Rural: 1990-2020, [2005].

- Demografía 1960, [1963].

— Resultados Definitivos del XIV Censo de Población 1970, [1971].

—_ Población. XV Censo Nacional de Población y IV de Vivienda - Chile 1982. Total País, Tomo II, [1986].

— Resultados Generales. Censo de Población y Vivienda - Chile 1992, [1993].

— Censo 2002. Resultados. Volumen I - Población, País - Región, [2003].

Estadísticas Vitales. Informe Anual 2009, [2011].

- Retratos de nuestra identidad: Los Censos de Población en Chile y su evolución histórica hacia el Bicentenario, 2009.

Jiménez, J., "Política y Organizaciones de Salud en Chile. Reflexiones Históricas", en ARS MEDICA. Revista de Estudios Médico Humanísticos, 5 (5) 53:64, 2001.

Laval, E., Las dos epidemias, en Revista Chilena de Infectología, Edición Aniversario, 2003.

Lesthaeghe R., van de Kaa D., "Twee demografische transities?" (Two demographic transitions?), en Lesthaeghe, R. y van de Kaa, D. (eds), Bevolking - Groei en Krimp, Mens en Maatschappij, Van Loghum Slaterus, Deventer, 9: 24, 1986.

Olavaria, M., Pobreza, crecimiento económico y políticas sociales, Santiago: Editorial Universitaria, 2005.

Revista Estadística Chilena - INE, Censo de Población de 1940, [1941].

Villalón, G. et al., Fecundidad en Chile. Situación reciente, INE, 2006. 